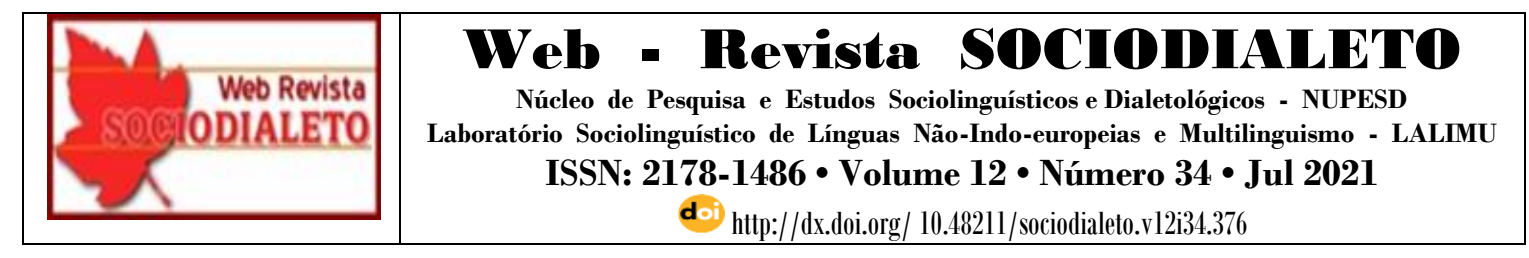

\title{
A VARIAÇÃO LINGUÍSTICA NO/DO FALAR CACERENSE: UM ESTUDO DO USO DOS ALOFONES AFRICADOS [dz] E [t]]
}

\section{LINGUISTIC VARIATION IN/OF THE CACERENSE SPEAKING: A STUDY OF THE USE OF THE AFRICATE ALOPHONES [d]] AND [t]]}

\author{
Júlio Cezar Rodrigues da Silva (PPGL-UNEMAT) ${ }^{1}$ \\ julio.rodrigues@unemat.br \\ Renata Geretti de Souza Jagnow (PPGL-UNEMAT) ${ }^{2}$ \\ geretti.renata@gmail.com \\ Catherine Rodrigues Lopes (PPGL-UNEMAT) ${ }^{3}$ \\ crlmonster@hotmail.com \\ Lúcia Flávia Campos da Silva (PPGL-UNEMAT) ${ }^{4}$ \\ lucia.flavia@unemat.br \\ Janaina de Lima Silva (PPGL-UNEMAT) ${ }^{5}$ \\ any251@ hotmail.com \\ Cristiane Schmidt (UNEMAT/UFPA) ${ }^{6}$ \\ schmidt@ufpa.com.br
}

\footnotetext{
${ }^{1}$ Doutorando em Linguística pelo Programa de Pós-graduação Stricto Sensu em Linguística e Literatura (PPGLL), da Universidade Federal de Alagoas (UFAL-2021-2024). Mestre em Linguística pelo Programa de Pós-graduação Stricto Sensu em Linguística (PPGL), da Universidade do Estado de Mato Grosso (Unemat-2019-2021). Graduado em Licenciatura em Letras Português/Inglês/Literaturas, pela Universidade do Estado de Mato Grosso (Unemat-2015-2019).

${ }^{2}$ Mestranda em Linguística pelo Programa de Pós-graduação Stricto Sensu em Linguística (PPGL), da Universidade do Estado de Mato Grosso (Unemat). Graduada em Licenciatura em Letras Português/Inglês/Literaturas, pela Universidade do Estado de Mato Grosso (Unemat-2018).

${ }^{3}$ Mestranda em Linguística pelo Programa de Pós-graduação Stricto Sensu em Linguística (PPGL), da Universidade do Estado de Mato Grosso (Unemat). Graduada em Licenciatura em Letras Português/Inglês/Literaturas, pela Universidade do Estado de Mato Grosso (Unemat-2018).

${ }^{4}$ Mestranda em Linguística pelo Programa de Pós-graduação Stricto Sensu em Linguística (PPGL), da Universidade do Estado de Mato Grosso (Unemat). Graduada em Licenciatura em Letras Português/Inglês/Literaturas, pela Universidade do Estado de Mato Grosso (Unemat-2019).

${ }^{5}$ Mestranda em Linguística pelo Programa de Pós-graduação Stricto Sensu em Linguística (PPGL), da Universidade do Estado de Mato Grosso (Unemat). Graduada em Licenciatura em Letras Português/Inglês/Literaturas, pela Universidade do Estado de Mato Grosso (Unemat-2018).

${ }^{6}$ Pós-doutora em Linguística pela Universidade Estadual do Mato Grosso do Sul (UEMS-2018). Doutora em Letras pela Universidade Estadual do Oeste do Paraná (UNIOESTE-2016). Docente Adjunto da Universidade Federal do Pará (UFPA). Docente Permanente do Programa de Pós-graduação Stricto Sensu em Linguística da Universidade do Estado de Mato Grosso (UNEMAT).
} 


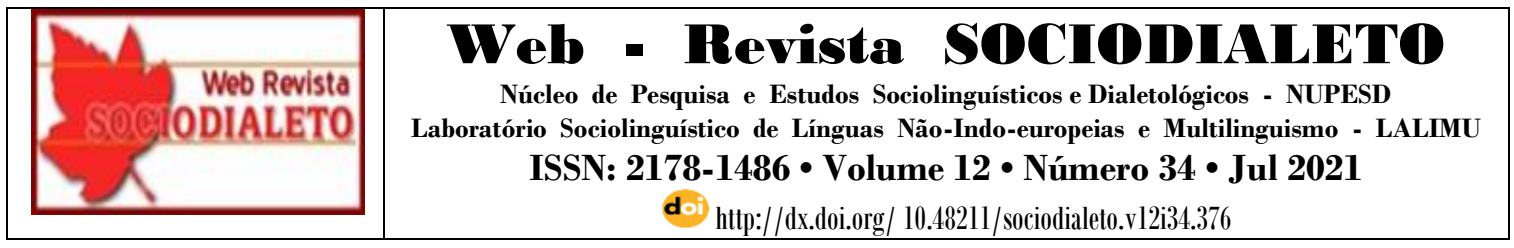

RESUMO: O presente artigo objetiva dissertar a respeito da variação linguística no falar cacerense, em suma, na observância dos alofones africados [d] e [t] . Na cidade de Cáceres, localizada no interior do estado de Mato Grosso, existem inúmeras variações linguísticas que ocorrem em lugares específicos devido à miscelânea de falares, tanto nativos, quanto de origem colonizadora. Por isso, a manifestação dos alofones africados, em determinados usos característicos da cidade, e, até mesmo da região, caracterizam o povo que mobiliza esse falar entre seus grupos sociais. Por meio da Teoria Sociolinguística, mobilizamos conceitos relevantes no que se refere ao componente em questão, bem como descrevemos e analisamos alguns usos recorrentes na cidade, não somente por falantes citadinos, mas também, por falantes do entorno urbano.

PALAVRAS-CHAVE: Variação Linguística; Falar Cacerense; Alofones Africados.

\begin{abstract}
The current article aims to discuss the linguistic variation in 'cacerense' speaking, in a word, in the observance of African allophones [d] and [t]. In the city of Cáceres, located in the interior of the state of Mato Grosso, there are numerous linguistic variations that occur in specific places due to the miscellany of speaking, both native and of colonizing origin. For this reason, the manifestation of African allophones, in certain characteristic uses of the city, and even of the region, characterizes the people who mobilize this speech among their social groups. Through Sociolinguistic Theory, we have mobilized relevant concepts regarding the component in question, as well as described and analyzed some recurrent uses in the city, not only by city speakers, but also by speakers from the urban environment.
\end{abstract}

KEYWORDS: Linguistic Variation; Cacerense Speak; African Alofones.

\title{
1 Introdução
}

A Sociolinguística, como uma Teoria Linguística, ao ocupar-se das relações entre a sociedade e a língua, tem como objeto de investigação, as variações e as mudanças que ocorrem no falar específico de um determinado lugar. A Sociolinguística enfatiza que o comportamento linguístico e sociocultural não é homogêneo, mas que existem diferenças, sendo que essas são sistemáticas e coerentes, em concordância com a sociedade heterogênea. Calcados nessa perspectiva, trazemos à tona, o estudo a respeito dos alofones africados [d孔] e [tg], no sentido de compreender o processo de variação, mudança e até mesmo de significância entre os sujeitos falantes de uma determinada língua e/ou dialeto regional, no caso, o falar cacerense.

No que se referem às variações linguísticas, elas estão relacionadas com fatores linguísticos e também extralinguísticos. Podemos destacar a idade, o sexo e a escolaridade a este respeito, bem como, com fatores de âmbito geográfico e sociais. Posto isso, essa ciência busca explicar a existência das variedades tomando esses preceitos como constituintes do processo e que se relacionam direta e/ou indiretamente com o que é de certame linguístico. 


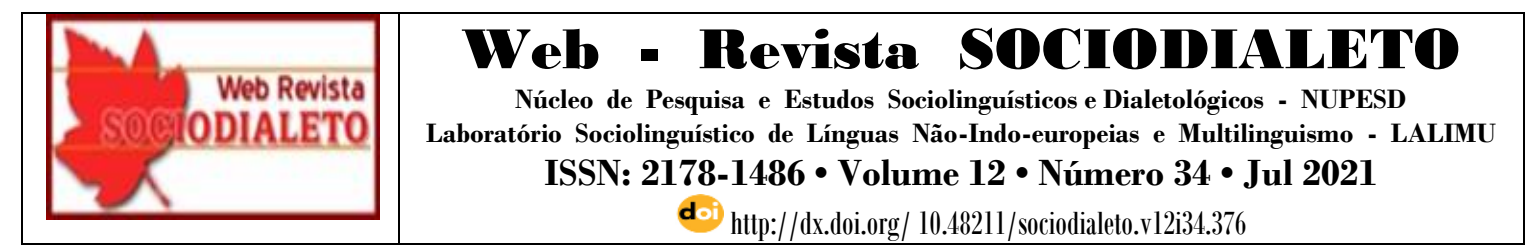

Por isso, desde meados do século passado, pesquisadores vêm se interessando pelas indagações nessa área, uma vez que o território brasileiro possui uma infinidade de fatores linguísticos atrelados, também, à complexidade social, aos processos constantes de variação, assim como a globalização das cidades que crescem dia após dia, corroborando, de certa forma, às inúmeras variações e mudanças na/da língua por meio dos sujeitos sócio-histórico-culturais.

O falar cacerense se configura em determinadas condições, às quais estão costuradas no interior deste artigo. Desse modo, a disseminação dos estudos sociolinguísticos, por meio de um panorama de comunidades linguísticas existentes no território brasileiro, se configura numa ideia de heterogeneidade linguística (SALOMÃO, 2011, p. 187).

Para tanto, a seguir, tecemos uma reflexão que abordará alguns aspectos do falar da comunidade cacerense onde são mobilizados os alofones africados [ḑ] e [ty] em ocorrências usuais do falar, bem como a propositura de análise de duas palavras às quais são muito usadas e percebidas no uso da comunidade em questão.

\section{Pressupostos da Sociolinguística Variacionista}

A Teoria da Variação tem sua origem em meados dos anos de 1960, em um congresso promovido na Universidade da Califórnia (Los Angeles), em que estavam presentes vários pesquisadores, como: John Gumperz, Dell Hymes, John Fisher e William Labov.

Como pesquisador expoente, destaca-se William Labov $(1969,1972)^{7}$, ao se preocupar, inicialmente, com a motivação social da mudança sonora na ilha de Martha's Vineyard, no estado americano de Massachussetts na década de 1960. Para ele, caso se correlacionasse o complexo padrão linguístico com diferenças na estrutura social, seria possível "isolar os fatores sociais que incidem diretamente sobre o processo linguístico" (LABOV, 2008, p. 19).

\footnotetext{
${ }^{7}$ A Sociolinguística Variacionista ou Teoria da Variação Laboviana, tornou-se sinônimo do estudo de variações e mudanças linguísticas, na qual depreende-se que para que o sistema mude, é necessário que ele tenha sofrido algum tipo de variação.
} 


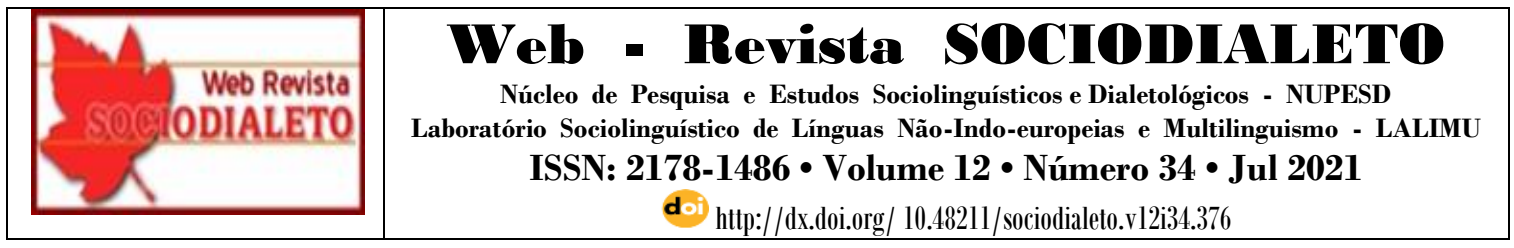

Em se tratando de variação linguística, esta não pode ser enxergada como um mero efeito de caso. A variação deve ser vista, com efeito, como um fenômeno cultural que é motivado, tanto por fatores linguísticos, quanto por fatores extralinguísticos, de modo que não se assemelhe a uma assistemática (SALOMÃO, 2011, p. 190).

A concepção de um sistema linguístico heterogêneo e variável faz com que necessariamente a Sociolinguística defina o seu objeto de estudo como a comunidade de fala, a coletividade que usa concretamente a língua em um contexto histórico específico, pois que "o objeto da descrição linguística é a gramática da comunidade de fala: o sistema de comunicação usados na interação social” (LABOV, 2008, p. 18).

Compreendendo a respeito da Teoria Sociolinguística, que sustenta este estudo e nossas afirmações, temos que:

\begin{abstract}
A pesquisa na Sociolinguística Variacionista busca apreender a sistematicidade da variação, seu encaixamento linguístico e social e uma possível relação com a mudança linguística por meio de análises quantitativas de um corpus, escolhido a partir de certas características sociais correlacionadas a uma variável linguística - que pode ser de ordem fonética-fonológica, morfossintática, entre outras (SALOMÃO, 2011, p. 191).
\end{abstract}

Portanto, como postulado central da Sociolinguística consta o "princípio de que a variação e a mudança são inerentes às línguas, e que, por isso, devem ser levadas em conta na análise linguística" (CEZARIO; VOTRE, 2009, p. 141). Ou seja, toda língua é dotada de dinamismo e consequente heterogeneidade sistemática.

Nesse sentido, destacamos que a variação intralinguística, especificamente, no seu aspecto fonético, tende a evidenciar a variação sistemática. A Fonética consagra-se enquanto a área que estuda os sons que o aparelho fonador humano pode produzir e que são passíveis de serem usados na comunicação linguística (MAIA, 1999). De forma geral, valemo-nos dos termos fone, como sendo a unidade sonora atestada na produção da fala, precedendo qualquer análise, e do conceito de alofone que representa a manifestação fonética de um fonema.

Para exemplificar, "o primeiro segmento de /'tia/ e /' dia/ constam execuções alofônicas diferentes, como [t] e [t $]$, [d] e [dz], em nada altera a oposição entre as 


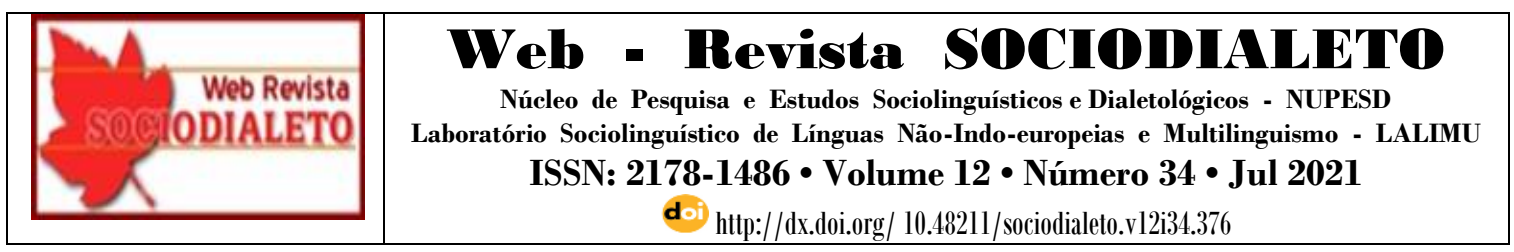

palavras, remetendo a diferenças de caráter fonético, ou seja, a alofones" (CASTILHO, 2010, p. 49).

De acordo com Alkmim (2011) que compreende a respeito de comunidades linguísticas:

Uma comunidade de fala se caracteriza não pelo fato de se constituir por pessoas que falam do mesmo modo, mas por indivíduos que se relacionam, por meio de redes comunicativas diversas, e que orientam seu comportamento verbal por um mesmo conjunto de regras (ALKMIM, 2011, p. 31).

Conforme o entendimento de Taralo (1994) “[...] a heterogeneidade não necessariamente exclui a noção de sistema; ao contrário, sistematicidade e heterogeneidade equacionam-se entre si, em um tipo de relação 1 = 1" (TARALO, 1994, p. 81).

\section{Comunidade de Fala Cacerense}

O falar cacerense emerge de uma miscelânea de línguas e dialetos, tanto locais, quanto de outros lugares, a saber, por exemplo, da antiga metrópole colonizadora, Portugal, bem como de imigrantes espanhóis, que foram aos poucos se misturando linguisticamente, rompendo com as fronteiras territoriais e, acima de tudo, de língua. Sendo assim, “[...] ao tentar padronizar a língua, o que ocorre é a propagação de preconceitos com aqueles que não fazem uso da norma considerada culta" (PEDROSO, 2018, p. 114-115).

O preconceito social, ou como podemos dizer, as atitudes linguísticas, conforme postula Bisinoto (2007) o falar cacerense se insere numa estigmatização de "falar feio", "falar errado", quando na verdade, o falar descrito do ponto de vista do falante não atinge tal premissa, porém, frente à sociedade dita culta, dominante da norma padrão, soa como estereótipo, algo negativo, relacionado, na maioria das vezes, com fatores que dizem respeito, principalmente, ao poder aquisitivo do sujeito.

Sem mencionar o fator de escolaridade do sujeito, que aparece em muitos estereótipos comprovados nos estudos contemporâneos sobre o falar cacerense. Há, nessa 


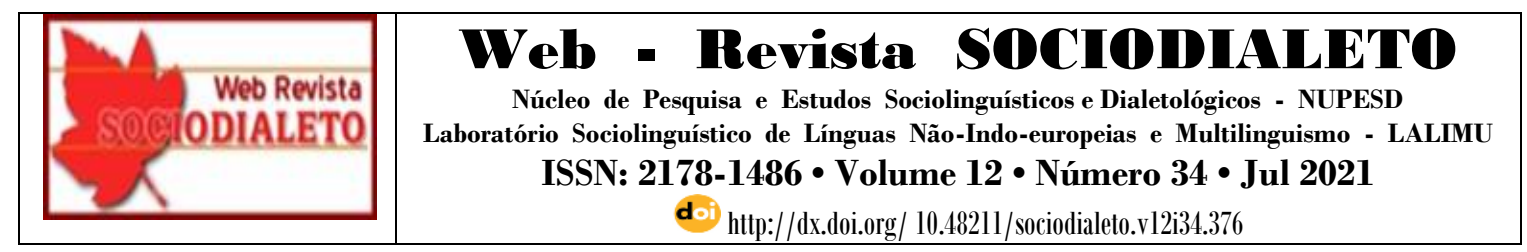

perspectiva, um tabu a ser quebrado em relação à fala em geral que, por muitas vezes, em sala de aula, alguns professores tentam corrigir o modo como um aluno fala e acaba inserindo um preconceito linguístico ao falante leigo.

Com isso, Barros (1985) destaca:

Corrigir a fala popular dos estudiosos menos experientes [...] estamos apenas, assinalando um fato, não uma condenação à redundância. Ela se impõe aos falantes que usam a linguagem culta e faz parte da estrutura da nossa língua (BARROS, 1985, p. 265).

Desse modo, visto que a fala por ser heterogênea, sempre haverá uma variedade, não só na palavra como podemos perceber nos fonemas que abrangem o campo histórico e linguístico da sociedade. Muitos elementos encontrados na região cacerense podem ser verificados em lugares específicos do norte do Estado de Galiza, visto que, tal região recebeu, em épocas outras, grande quantidade de falantes nativos daquela região à qual se fez presente em terras mato-grossenses no período pós-colonial.

Além disso, a cidade de Cáceres tem um diferencial das demais cidades do Estado de Mato Grosso. É uma cidade que faz divisa com a Bolívia, sendo considera uma cidade fronteiriça. A percepção de miscigenação linguística é notável à medida em que nos deparamos com inúmeros indivíduos bolivianos circulando nas ruas da cidade. Por isso, as questões de língua, quando pensadas nesse território, rompem fronteiras físicas e ideológicas, pois a língua perpassa os dois países que se relacionam por meio dos sujeitos que os habitam.

Ao startar as discussões, tomemos as afirmações dos autores Weinreich, Labov e Herzog, (2006, [1968]), que tomam que:

[...] A língua funciona enquanto muda. [...] A variação faz parte do sistema linguístico, que é heterogêneo e composto por regras e unidades variáveis. [...] A mudança linguística pode ser estudada diretamente através da análise da variação observada em cada estado de língua (WEINREICH; LABOV; HERZOG, 2006, [1968], p. 35).

Tendo em vista essa afirmação, num gesto de paráfrase, podemos afirmar que o falar cacerense funciona enquanto muda (grifos nossos). O funcionamento da língua 


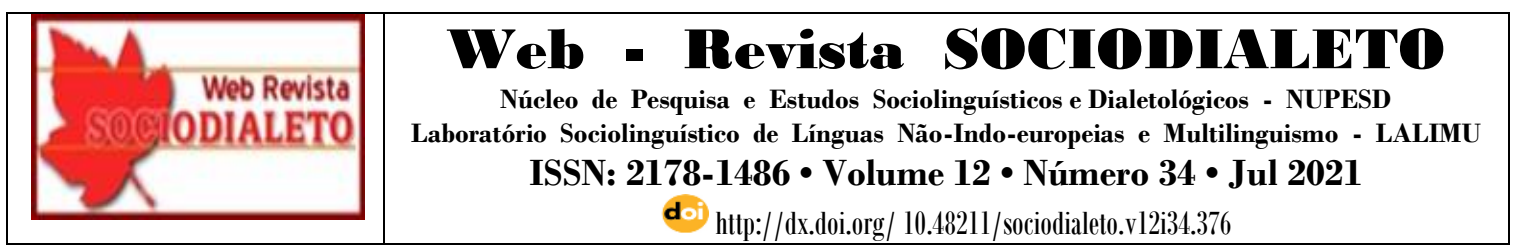

acontece à medida em que os seus falantes recorrem à ela para se comunicarem, pois no que se refere ao funcionamento de uma língua(gem), esta muda ao passo em que o falante, ao enunciar e ao produzir um discurso, a relação constitutiva entre língua, sujeito, história e, por conseguinte, do sentido, vão se constituindo, mudando os elementos linguísticos já existentes no próprio léxico.

Segundo Pedroso (2018):

A Sociolinguística busca explicar a relação entre linguagem e sociedade, evidenciando que a linguagem é reflexo das estruturas sociais. Para essa área da linguística a língua é heterogênea e está em constante processo de transformação, assim a Sociolinguística não vê a diversidade como um problema, uma vez que todas as línguas possuem variações (PEDROSO, 2018, p. 12).

Quando observamos o falar cacerense, assim como outros falares, logo associamos as variações e/ou atitudes linguísticas ao fator social de oportunidades, bem como de poder aquisitivo. À nossa perspectiva, esse ponto de vista não se sustenta, visto que a observância dos alofones africados não é pertinente somente aos moradores afastados do centro, por exemplo, que possuem poder aquisitivo superior aos moradores de bairros afastados e, até mesmo, das redondezas da cidade.

O que há, são gestos sociais que são característicos de um ou mais grupos que se marcam pelo que falam e não pelo que representam dentro de um determinado contexto social. Desse modo, a Sociolinguística faz uma correlação do que cada falante da sociedade ali inserida para depreender a variação dita pela mesma pessoa ou por várias.

Camacho (2001) relata que:

A Sociolinguística Variacionista vê a relação entre estrutura linguística e social da seguinte maneira: dois falantes de uma mesma língua ou variedade dialetal dificilmente se expressam da mesma maneira; do mesmo modo, um único falante raramente se expressa da mesma maneira em duas diferentes circunstâncias de comunicação (CAMACHO, 2001, p. 50). 


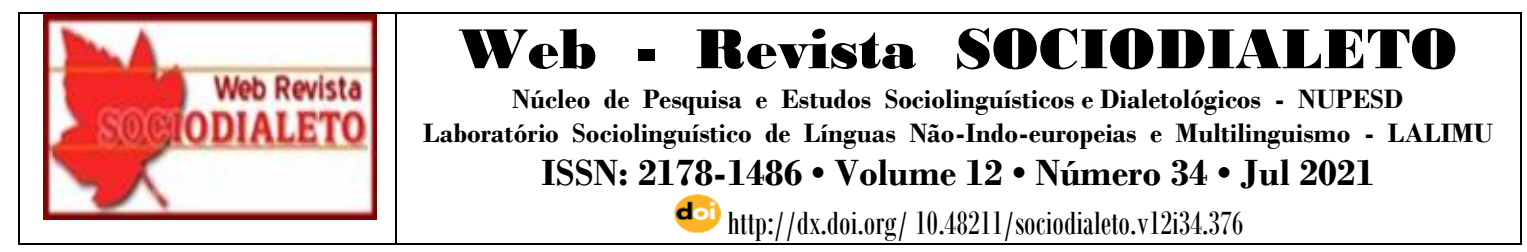

Toda língua é passiva de variação, por ser viva e estar em constante mudança, abrindo alas para uma diversificação de variação, porém em virtude dos estudos fonéticos/fonológicos, sabe-se que possuímos apenas os alofones africados que são abordados neste texto.

Camacho (2001) afirma ainda, que:

[...] o que a Sociolinguística faz é correlacionar variações existentes na expressão verbal a diversidades sociais, entendendo cada domínio, tanto o linguístico como o social, como fenômenos estruturados e regulares (CAMACHO, 2001, p. 50).

Desse modo, pensando nessa perspectiva, Camacho (2001) nos esclarece que o domínio que nos interessa está relacionado à expressão verbal dos indivíduos nos mais variados contextos sociais de fala. Entendendo os aspectos linguísticos e sociais e os fenômenos que se estruturam por meio do falar que se deseja estudar, compreende-se e concebe-se, por consequência, o modo como os falantes se comunicam e interagem na produção de conhecimentos à sociabilidade entre seus pares.

Ademais, conforme nos ensina, ainda, Camacho (2001):

Se um falante enuncia o verbo "vamos" como [vãmus] e o outro falante o enuncia como [vãmu], afirmamos, com base na teoria da Sociolinguística, que essa variação existente na fala não é o resultado aleatório de um uso arbitrário e inconsequente dos falantes, mas um uso sistemático e regular de uma propriedade inerente aos sistemas, que é a possibilidade de variação (CAMACHO, 2001, p. 50).

Portanto, nessa ocorrência do uso sistemático e regular dos falantes, é onde encontramos as variações em seu funcionamento no seio social. Elas significam à medida em que são acionadas e postas em circulação por uma determinada comunidade que entende e compreende os significados a ela atribuídos.

\section{A fala cacerense se manifestando}




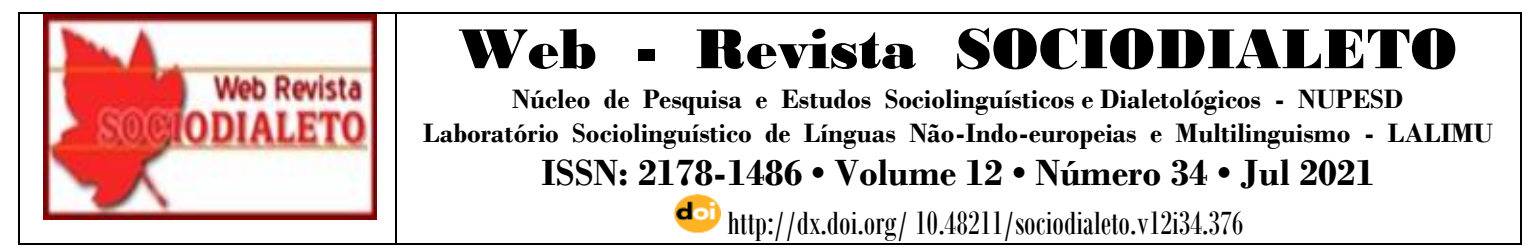

O falar de um povo é a identidade desse povo. É uma vertente tão identitária que não há, por parte do falante da variante, o gosto em querer mudar e/ou aprimorar, a não ser que haja a necessidade conforme os indivíduos forem requerendo elementos da língua para dizerem o que querem. Essa afirmação circunda muitas pesquisas feitas a respeito das variantes nas comunidades linguísticas, em suma, da comunidade cacerense (PEDROSO, 2018).

Tanto os nativos da região, quanto os que se valem dessa variante em seu dia a dia, demonstram, mesmo que inconscientemente, um sentimento de orgulho com o próprio falar. É essa diferença que os diferenciam do resto da comunidade linguística da localidade, deixando um caráter único e não copiado, próprio de um determinado ambiente social (PEDROSO, 2018).

Pensamos também, que a pertinência do falar se sustenta pelo uso da comunidade mais antiga da cidade, no sentido de preservação, de prática, de identidade, pois ao ouvirmos essas particularidades materializadas na fala, percebemos o gesto original e definidor de um morador que habita a comunidade linguística cacerense. É notório que a constante variante se encontra nos moradores mais velhos, porém, a comunidade mais jovem também mantém enraizado, em seu falar, os alofones africados entre seus pares (PEDROSO, 2018).

A exemplo disso, podemos destacar alguns usos recorrentes no falar cacerense, do mais velho ao mais novo falante. Desse modo, observamos no dia a dia cacerense: Vôte ['vo:tfi] ou ['votə], Chuva ['tfuva], Gente ['dzẽtfi] ou [dzẽte], Chá ['tfa], Jeito ['dzeitu] e Xaí ['tfaI]. A dois desses exemplos, propomos interpretações possíveis, pois há várias situações em que os falantes empregam cada um deles.

Dessa forma, observamos os fonemas [t] e [d]], na comunidade cacerense, em que as pessoas utilizam em suas falas os fones /t/ e /d/, porém como alofones que se realizam como oclusivas dentais [t] e [d] , seguidos de vogal anterior alta [i]. No entanto, percebemos a ocorrência de africadas em posições não previstas na matriz fonológica do português. 


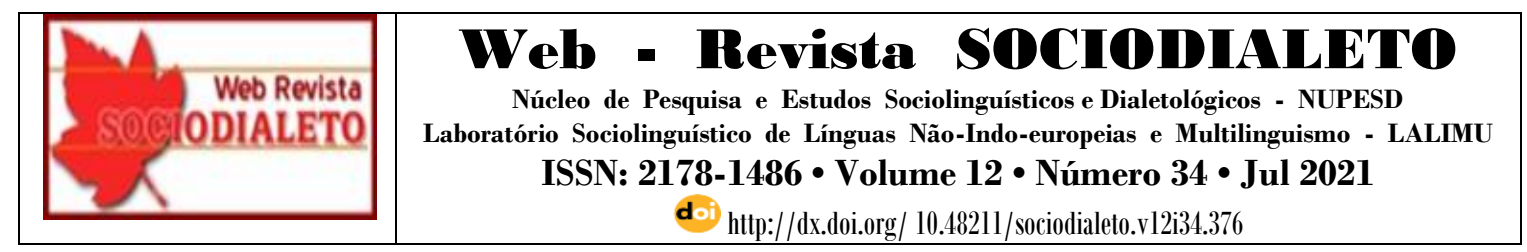

As africadas [t] e [ḑ] são as variações dos fones /t/ e /d/ e elas ocorrem, em alguns casos, entre o fone vocálico anterior alta /i/, essa variação não muda nenhum sentido da palavra, mas faz com que elas sejam a identidade única do falante. Portanto, tendo em vista essa afirmação, podemos encontrar autores que definem esse fenômeno variante dentro de várias comunidades e o comportamento linguístico delas podem ocorrer diversas vezes numa mesma frase.

Bagno, Gangné e Stubbs (2002) nos diz que "Uma das tarefas do ensino de língua na escola seria, então, discutir os valores sociais atribuídos a cada variante linguística [...]” (BAGNO; GANGNÉ; STUBBS, 2002, p. 75). Sendo assim, a importância do professor em ensinar e explicar para que não se criem e/ou tenham preconceitos linguísticos com os demais indivíduos que compõem o grupo social escolar é imprescindível, pois por muitas vezes, alguns alunos são oriundos de outra cidade e/ou estado, no qual possivelmente não existem as variantes fricativas.

Desse modo, verificamos com facilidade, na cidade de Cáceres, essas fricativas em movimento nos grupos sociais urbanos e do entorno da cidade, independente de idade e/ou escolaridade. Mori (2004) trata os alofones como uma variação livre, fazendo com que a estrutura demonstre um modo estilístico e sistemático das variantes utilizadas frequentemente.

Nesse sentido, encontramos esse fenômeno em palavras como tia ['tfia] e dia ['dzia]. No entanto, elas também aparecem em palavras como tira [ţira] e diante [dziãtfi]. A palavra 'diante' mostra que ao serem usadas em uma frase, não se muda o léxico da palavra. Podemos observar a fala dentro do esquema arbóreo, mostrando as tonalidades e como não muda o sentido. A tônica permanece na vogal oral anterior alta /i/ e decai no fone vocálico baixo /a/. Portanto, se o indivíduo disser ['tia] ou ['tfia] permanece o mesmo sentido.

Veremos isso a abaixo: 


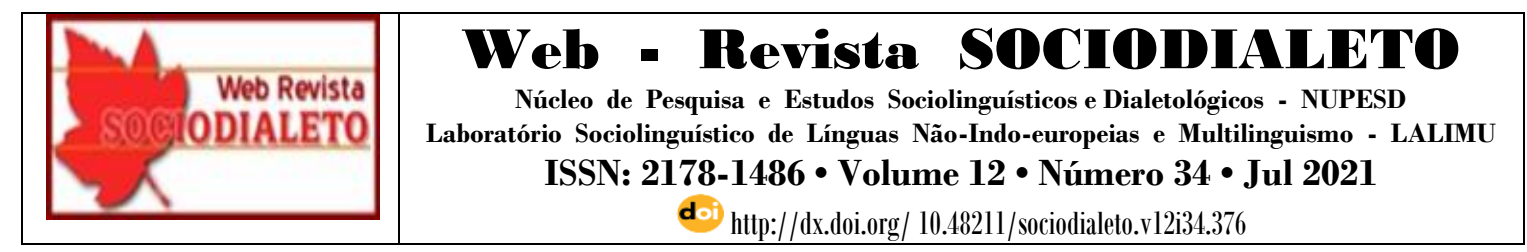

\section{Figura 1 - Esquema arbóreo da palavra "tia"}

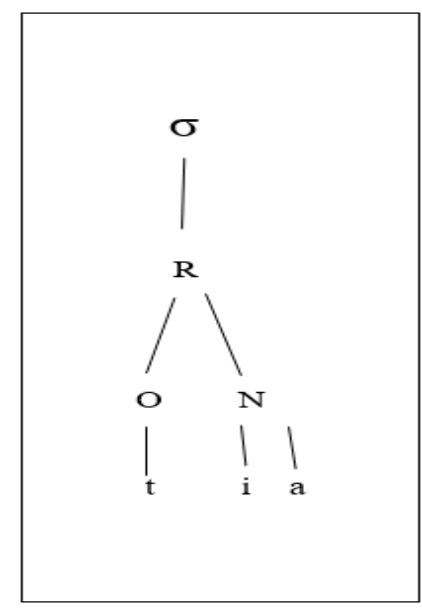

Fonte: (Autores, 2021) com base na Transcrição Fonológica de Selkirk (1982).

Para Gisela Colloschonn (2001) é permitido que alguns segmentos possam ficar vazios, como podemos ver na palavra "tia". Bisol (2001) afirma que no molde silábico:

As sílabas diferem quanto ao número de segmentos permitido em cada constituinte silábico. Há línguas que permitem apenas um segmento no ataque e outro na rima. Há línguas que permitem um segmento no ataque e dois na rima. Por outro lado, há línguas que permitem dois segmentos no ataque, um no núcleo e até três segmentos na coda (BISOL, 2001, p, 95).

Assim, as africadas, na fala, sempre ocorrerão como onset ou coda, nunca no núcleo, afirmando que as variantes não mudam o contexto da palavra. Essa base é importante e acarreta muito nas pesquisas, para compreendermos a situação do(s) falante(s).

A fonética é uma ciência que muito tem auxiliado os estudos sociolinguísticos, facilitando a compreensão da fala dos entrevistados, mesmo visando o contexto social da língua em geral. Por isso, recorremos às transcrições fonéticas para abraçarmos os materiais de análise, bem como evidenciar a ocorrência dos alofones africados em palavras que permeiam o falar da comunidade cacerense. 


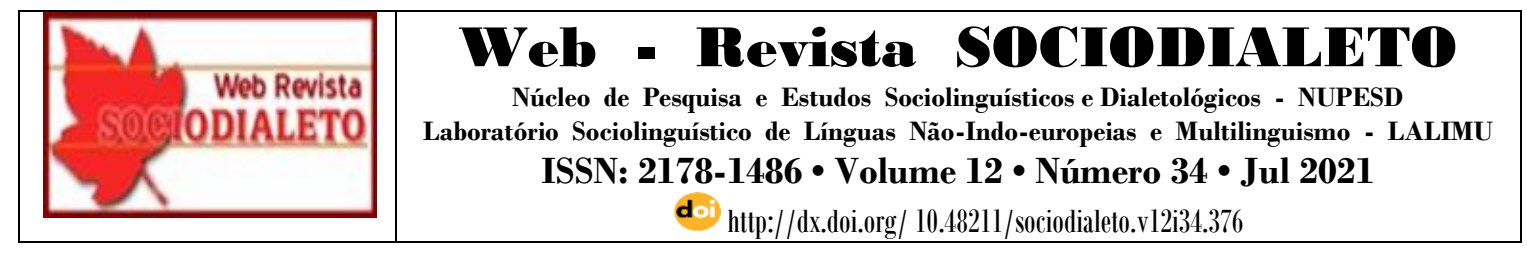

É importante destacar que a variação linguística é o movimento comum e natural de uma língua, que varia principalmente por fatores históricos e culturais, verificados em nosso estudo, pelas interferências de ordem sócio-histórica-ideológica dos sujeitos falantes da variante cacerense. Ao passo em que percebemos esse gesto de uso dos falantes, vemos também, a sua relação com fatores, tanto linguísticos, quanto extralinguísticos, como mencionado anteriormente.

Os falares dos alofones africadas na região da comunidade da cidade de CáceresMT, são, de certa forma, produto da miscelânea de fatores de ordem histórica e cultural que, de acordo com as influências, usos e desusos foram evoluindo ao longo do tempo. Por isso, o sociolinguista não pode fazer a sua análise voltada às relações de estigmatização linguística, tampouco de mobilidade social, por exemplo, mas sim, com um foco no que é de originalidade da comunidade, ressaltando a força que o falar exerce e toma para si, dos falantes que dela fazem uso (MOLLICA, 2004).

Encaminhando-nos a um fechamento, a respeito das ocorrências percebidas no falar cacerense, ponderamos, conforme Mollica (2004) que:

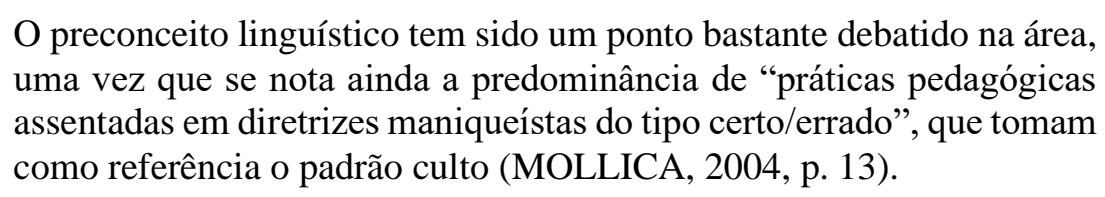

Ou seja, procuramos, com o nosso estudo, entender, analisar e valorizar o percurso natural da língua e das suas variações que as tornam única. Não há, na língua, nem certo, nem errado no falar dos indivíduos em suas comunidades de fala, por isso, os linguistas e/ou sociolinguistas, devem respeitar, entender e valorizar cada falar característico de um determinado local, pois as variantes constantes são constitutivas dos falantes que vivem nele, sejam nativos ou não.

Como afirmam Bagno, Gangné e Stubbs (2002) "o mais importante de tudo é preservar [...] insistir que elas não são erros. [...] e que não há certo/errado na forma como nos comunicamos verbalmente" (BAGNO; GANGNÉ; STUBBS, 2002, p. 25). 


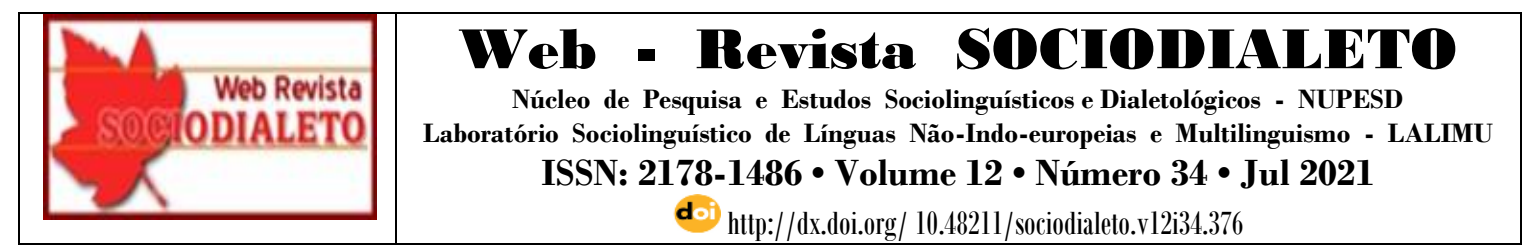

\section{Considerações Finais}

É notório a conservação dos alofones no falar cacerense, o qual vai além do poder aquisitivo e posição social, é uma característica que difere não só os indivíduos cacerenses, mas a população mato-grossense o uso dos alofones africados [t $\left.\int\right]$ e [dz] no seu cotidiano. Em Cáceres-MT e região, a frequência desses alofones já faz parte da cultura social, pois no cotidiano esses alofones são enraizados nos nativos, pois crescem ouvindo e aprendendo a manter essa identidade pertencente no falar cacerense.

Desse modo, cabe aos pesquisadores e professores dos estudos da linguagem do ponto de vista social, semearem em seus alunos e leitores, a importância da variação linguística que ocorre em cada região, mostrando que ela vai além do poder aquisitivo do indivíduo, e sim um fator que envolve a história local, os fatores de língua, pois ela é viva e permanece em constante mudança. Ou seja, a compreensão das variantes/dialetos terá um resultado significativo no tocante ao preconceito linguístico.

\section{Referências}

BARROS, E. M. Nova gramática da língua portuguesa. São Paulo: Atlas, 1985. p. 281283.

CAMACHO, R. G. Sociolinguística. In: MUSSAliM, F.; BENTES, A. C. (orgs.). Introdução à linguística: domínios e fronteiras. São Paulo: Cortez, 2001.

ALKMIM, T. M. Sociolinguística. In: MUSSALIN, F.; BENTES, A. C. (orgs.). Introdução à linguística: domínios e fronteiras. 9. Ed., São Paulo: Cortez, 2011. p. 2147.

AMÂNCIO, R. G. As “cidades trigêmeas": Um estudo sobre atitudes linguístico-sociais e identidade. Dissertação (Mestrado em Estudos da Linguagem), Universidade Estadual de Campinas (Unicamp), Campinas: Instituto de Estudos da Linguagem, 2007.

BAGNO, M.; GANGNÉ, G.; STUBBS, M. Língua materna, letramento, variação e ensino. São Paulo: Parábola Editorial, 2002.

BISINOTO, L. S. J. Atitudes sociolinguísticas: efeitos do processo migratório. Campinas: Pontes, 2007.

BISOL, L. Introdução os estudos de fonologia do português brasileiro. 3. Ed., 2001. 


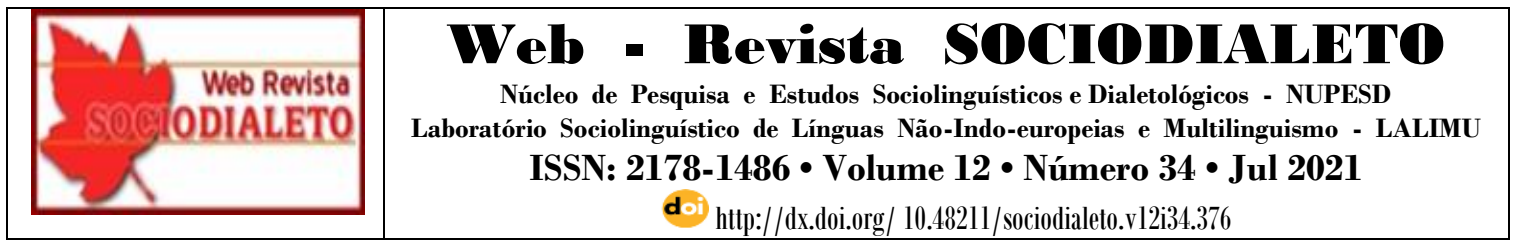

CASTILHO, A. T. de. A nova gramática do português brasileiro. São Paulo: Contexto, 2010.

CEZARIO, M. M.; VOTRE, S. Sociolinguística. In: MARTELOTTA, M. E. Manual da linguística. São Paulo: Contexto, 2009.

LABOV, W. Padrões sociolinguísticos. São Paulo: Parábola, 2008.

MAIA, E. M. No reino da fala: a linguagem e seus sons. 3. Ed., São Paulo: Ática, 1991.

MENDES, S. C. O uso de [ÃW] e [Õ] no falar da comunidade Corixa: atitudes e crenças linguísticas. LING. - Est. e Pesq., Catalão, v. 22, n. 2, jul./dez., 2018. p. 205-223. Disponível em: https://www.revistas.ufg.br/lep/article/download/57506/32748/. Acesso em: 24 jun. 2020.

MOLLICA, M. C. Fundamentação teórica: conceituação e delimitação. In: MOLLICA, M. C.; BRAGA, M. L. (orgs.). Introdução à sociolinguística: o tratamento da variação. 2. Ed., São Paulo: Contexto, 2004. p. 9-14.

MORI, A. C. Fonologia. In: MUSSALIN, F.; BENTES, A. C. Introdução à linguística: domínios e fronteiras. São Paulo: Cortez, v. 1, 2004.

PEDROSO, F. de S. Mídias faladas locais: um estudo sobre linguísticas em CáceresMT. Dissertação (Mestrado em Linguística), Programa de Pós-Graduação em Linguística, Universidade do Estado de Mato Grosso (Unemat), 2018. 143 p. Disponível em: http://portal.unemat.br/media/files/Fernanda-de-Souza-Pedroso-Campelo.pdf. Acesso em: 26 jun. 2019.

SALOMÃO, A. C. B. Variação e mudança linguística: panorama e perspectivas da sociolinguística variacionista no Brasil. Fórum Linguístico, Florianópolis, v. 8, n. 2, jul./dez., 2011. p. 187-207. $\quad$ p. Disponível em: https://periodicos.ufsc.br/index.php/forum/article/view/19848412.2011v8n2p187/21673. Acesso em: 25 jun. 2019.

SALOMÃO, A. C. Variação e mudança linguística: panorama e perspectivas da sociolinguística variacionista no Brasil. Fórum Linguístico, Florianópolis, v. 8, n. 2, p. 187-207, jul./dez., 2011.

SELKIRK, E. The Syllable. In: HULST; SMITH. (orgs.). The structure phonological representations (Part II). Dordrecht Foris, 1982. p. 337-383.

TARALlO, F. A pesquisa sociolinguística. 3. Ed., São Paulo: Ática S.A., 1990.

WEINREICH, U.; LABOV, W.; HERZOG, M. Fundamentos empíricos para uma teoria da mudança linguística. São Paulo: Parábola, 2006. [1968].

Recebido em: 08/02/2021 | Aprovado em: 23/05/2021. 